Key words: sandwich meta-structure, classic sandwich strip, ratio of interfacial contact, interlayer bonding factor, coefficient of impact sensitivity, flexural stiffness.

\title{
COMPARATIVE GEOMETRICAL AND EXPERIMENTAL STUDY ON A NEW SANDWICH META-STRUCTURE AND ITS CLASSIC THREE-LAYER COUNTERPART
}

\begin{abstract}
The aim of this paper is to compare some geometric parameters and deflections of a sandwich meta-structure with its classic, three-layer counterpart. Both structures are composed of the same materials and have the same external dimensions and mass, but their middle layers (cores) are different. The core of the sandwich meta-structure is a new spatial structure itself, consisting of there-layer bars. The core of the classic sandwich structure is a layer of the continuum. To make the comparison more general and convincing, three geometrical parameters, i.e., ratio of interfacial contact (Ric), interlayer bonding factor (Ibf) and coefficient of impact sensitivity (Cis), were introduced and applied. Deflections of the structures, simply supported at the edges and loaded in the mid-span by a static force, have been measured and are presented in the paper. Potential advantages of the new meta-structure are briefly outlined.
\end{abstract}

\section{Introduction}

Sandwich structural elements are becoming more common in bodies for railway wagons [1], buses [2], and in the construction of aircraft [3]. Recently, sandwich structural elements attracted the attention of researchers as noise barriers [4-9]. In all the above mentioned applications, the middle layers were of polymer foams or cellular (honeycomb) structure. Unfortunately, the core materials are sensitive to impact and unfavorable to them are debonding appearing between the core and facings. In the sample papers [10-11], we can find many details about defects in sandwich structures with the foam and cell cores and some consequences of these defects. Improved mechanical properties have sandwich structures with 3D cores, produced from the 3D woven fabrics [12].

* Institute of Vehicles, Warsaw University of Technology, Narbutta 84, 02-524 Warsaw, Poland, E-mail: karczmarzyk_st@poczta.onet.pl 
It is noted that the sandwich structures also include those that have, instead of the continuous or cellular or 3D cores, different, usually unidirectional, homogeneous profiles placed between the outer layers and fixed to them. In paper [13], one can find the nomenclature of these cores. Hence, we have sandwich panels with continuous-corrugated-core, top-hat-core, zed-core, channel-core (or C-core) and with truss-core. In paper [14], some mathematical details on the $\mathrm{C}$-core sandwich panel have been given. Some results of numerical investigations of sandwich panels with I-core are presented in [15]. An interesting result of this study is that filling the space between the I-bars with a foam implies a significant increase in critical buckling stress for this structure.

The purpose of this article is to describe a new three-layer sandwich structure with a discontinuous core. Facings of this structure are conventional, isotropic but the core is new in comparison with the cores outlined above. It is composed of two groups of heterogeneous, three-layer bars. The bars of one group (family) are perpendicular to the bars of the second group. To the best of the author's knowledge, the core is the new spatial 3D composite structure. The author believes that, because of the geometric and physical complexity of the core, it is better to call the sandwich panel by the term sandwich meta-structure. In a number of places in the text, the new core is referred to by the terms: grid core, grate core, lattice core, cellular core, or composite core. It is noted that the structure of the core is one of the claims in the patent application [16].

The paper describes a fresh idea and initial geometric and experimental evaluation of this idea. The new core of the meta-structure proposed in [16] and analyzed here, consisting of three-layer intersecting bars, differs from all the cores in the literature [13, 17-22]. This core is not corrugated [13], TorHex [17-18], 3D integrated [19], tetrahedral truss [20], hexagonal honeycomb [21] or square honeycomb [22]. (It is noted that the square honeycomb core in paper [22] is of a homogeneous material while the new lattice core, described in the present paper, is composed of non homogeneous, intersecting, three-layer bars.).

The work consists of two substantive parts. One of them contains formal considerations, concerning geometry of the new core. For the purpose, three geometrical parameters i.e., ratio of interfacial contact (Ric), interlayer bonding factor (Ibf) and coefficient of impact sensitivity (Cis), were introduced and applied. The purpose of the geometric analysis is to show some properties as well as the possibilities and limitations of making of the new lattice core, which would not be heavier than a conventional core of polyurethane foam. The latter substantive part contains experimental results (deflections) for a sandwich strip with the new composite core and for the classic three-layer strip. Short discussion of the results is also given. It is stressed that the 
experimental studies were conducted mainly to answer the question what is the relationship between flexural stiffnesses of the two structures, composed of the same materials and having the same mass: the new meta-structure, and the classic three-layer sandwich structure.

The layout of the paper is as follows. In section 2, the ratio of interfacial contact (Ris) for the homogeneous grid (rectangular honeycomb) core is defined. The definition is also applicable to the non-homogeneous grid core which is considered in detail in section 3 . In section 4, two additional geometric parameters, interlayer bonding factor (Ibf) and coefficient of impact sensitivity (Cis), are introduced and their dependence on geometric parameters of the composite core is analysed. In section 5, the condition of equality of the masses of the continuous core and grid one and consequences of the condition are considered. Section 6 contains description of the meta-structure investigated experimentally. In section 7, the experimental results are presented and briefly discussed. Section 8 contains some conclusions.

\section{Grid core and its ratio of interfacial contact}

Consider first the core as a homogeneous grid structure - as shown in Fig. 1.

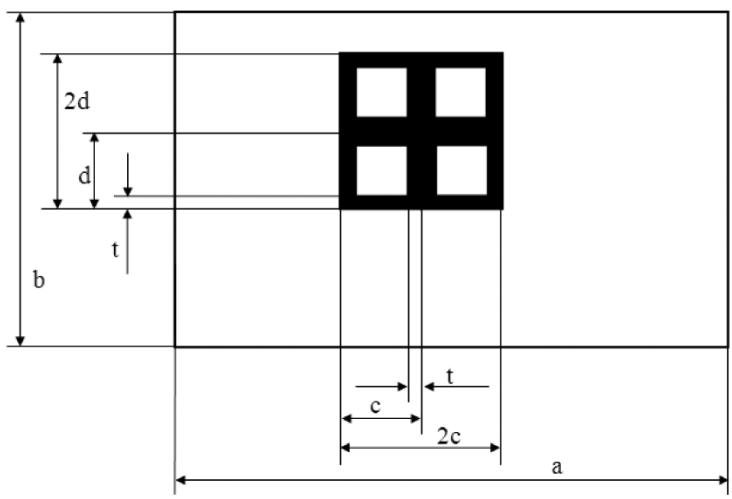

Fig. 1. Core in the form of a grate

Let us assume that the following equalities are satisfied,

$$
a=m_{1} c, \quad b=m_{2} d, \quad m_{i}=1,2,3, \ldots, \quad i=1,2 .
$$

One can see in Fig. 1 that the area consisting of $N=m_{1} \times m_{2}$ rectangles of dimensions $c \times d$ is equal to the product $a b$. The height of the cells $(c-2 t) \times$ $\times(d-2 t)$ is equal to the thickness of the core. The ratio of interfacial contact (Ric) between the core and each of the faces is defined as follows, 


$$
\begin{aligned}
\text { Ric }=1 & -(c-2 t)(d-2 t) / c d \stackrel{c=d}{=} 1-(c-2 t)^{2} / c^{2}= \\
& =1-(1-2 t / c)^{2}=4(t / c)(1-t / c) .
\end{aligned}
$$

It is noted that, if $2 t / c=0.2$ then Ric $=0.36$. It is much less than for the classic three-layer sandwich counterpart, with continuous core, where Ric $=1$. Formula (2) is also valid if the lattice core is the nonhomogeneous structure presented in section 3 .

\section{New non-homogeneous core of the meta-structure}

The new core of the meta-structure is shown in Fig. 2.

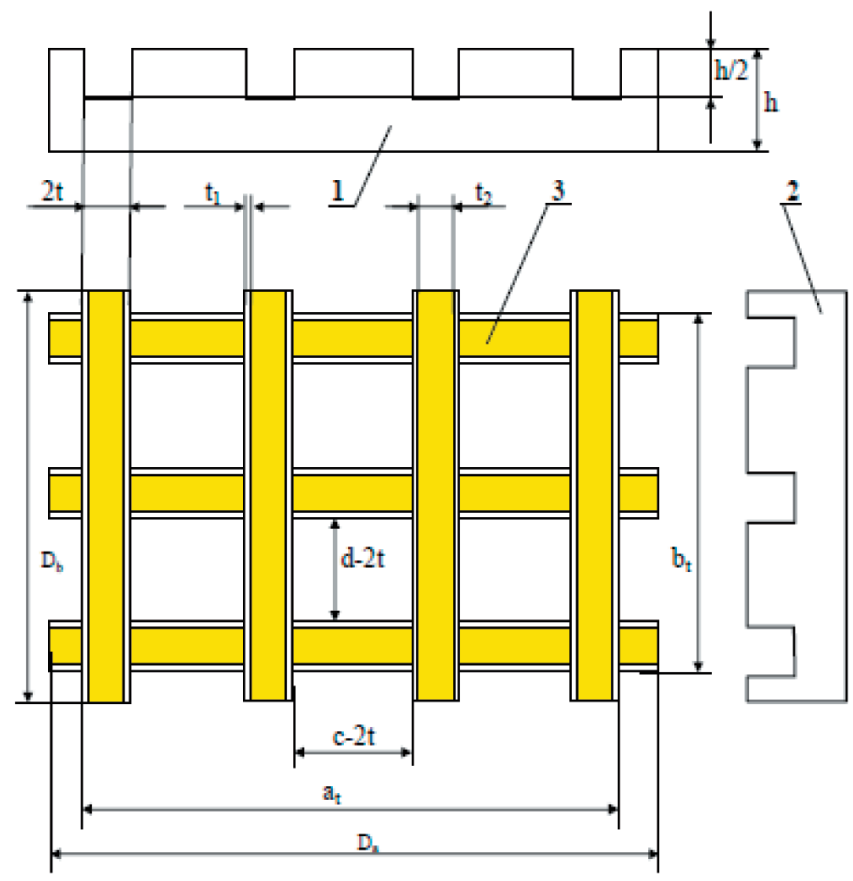

Fig. 2. New core of the meta-structure: 1 - side view of three-layer bars with top rectangular or square cut-outs, 2 - side view of three-layer bars with bottom rectangular or square cut-outs, 3 - plane view of assembly of the bars

As it is seen in Fig. 2, the core of the meta-structure consists of two families of three-layer bars which are connected within the cut-outs by means of glue. The bars of one family are perpendicular to the bars of the latter family and, therefore, the core is a non-homogeneous grid, where $2 t=2 t_{1}+t_{2}$ whereas $t_{1}$ and $t_{2}$ are thicknesses of the outer layers and the middle layer of the bars, 
respectively. Hence, the ratio of interfacial contact between the non-homogeneous core and facings of the whole meta-structure is defined by formula (2). It is reasonable for technological reasons to assume that the sizes of the cut-outs in all the bars are the same, regardless of the family to which they belong. It is noted that $a_{t}, b_{t}$, see Figs 1-2, are defined as follows,

$$
\begin{aligned}
& a_{t}=a+2 t=m_{1} c+2 t, \\
& b_{t}=b+2 t=m_{2} d+2 t \stackrel{d=c}{=} m_{2} c+2 t, \\
& 2 t=2 t_{1}+t_{2}, \\
& m_{i}=1,2,3, \ldots, \quad i=1,2 .
\end{aligned}
$$

The product $m_{1} m_{2}=(m-1)(n-1)$ is equal to the number of cells of dimensions $(c-2 t) \times(d-2 t)$ while the product $m n$ is equal to the number of the bars - see Fig. 2.

\section{Additional geometric parameters for the new meta-structure}

In order to present better the new meta-structure, two additional geometric parameters are useful. One of them is called the interlayer bonding factor (Ibf). It is defined as follows,

$$
\begin{gathered}
I b f=\left(\sum_{i=1}^{i=n} 2 A_{b 1 i}+\sum_{j=1}^{j=m} 2 A_{b 2 j}+\sum_{k=1}^{k=K} A_{b c k}+\sum_{l=1}^{l=L} A_{c f l}+4 t\left(a_{t}+b_{t}-2 t\right)+\right. \\
\left.+4 n\left(D_{a}-a_{t}\right) t+4 m\left(D_{b}-b_{t}\right) t\right) / D_{a} D_{b}, \\
I b f \underset{\substack{D_{a}=a_{t} \\
D_{b}=b_{t}}}{i=n}\left(\sum_{i=1}^{i=n} 2 A_{b 1 i}+\sum_{j=1}^{j=m} 2 A_{b 2 j}+\sum_{k=1}^{k=K} A_{b c k}+\sum_{l=1}^{l=L} A_{c f l}+4 t\left(a_{t}+b_{t}-2 t\right)\right) / a_{t} b_{t} .
\end{gathered}
$$

The symbols appearing in (4) denote: $A_{b 1 i}$ - area of contact between two adjacent layers of $i^{\text {th }}$ bar of family $1, A_{b 2 j}$ - area of contact between two adjacent layers of $j^{\text {th }}$ bar of family $2, A_{b c k}$-area of the connection of two bars in $k^{\text {th }}$ perpendicular intersection, $A_{c f}$ - area of contact between $t^{\text {th }}$ cell of dimensions $c \times d$ of the core and faces of the meta-structure, respectively. It is clear that

$$
A_{b 1 i}=D_{a} h-m h t=h\left(D_{a}-m t\right) \Leftrightarrow \sum_{i=1}^{i=n} 2 A_{b 1 i}=2 n h\left(D_{a}-m t\right),
$$




$$
\begin{gathered}
A_{b 2 j}=D_{b} h-n h t=h\left(D_{b}-n t\right) \Leftrightarrow \sum_{j=1}^{j=m} 2 A_{b 2 j}=2 m h\left(D_{b}-n t\right), \\
A_{b c k}=4 t^{2}+4 h t=4 t^{2}(1+h / t) \Leftrightarrow \sum_{k=1}^{k=K} A_{b c k}=4 m n t^{2}(1+h / t), \\
\sum_{l=1}^{l=L} A_{c f l}=2 L c d \cdot R i c, \quad K=m n, \quad L=(m-1)(n-1), \quad m=m_{1}+1, \quad n=m_{2}+1 .
\end{gathered}
$$

The symbols $m, n$ denote the number of bars in the families.

The Ibf geometrical parameter is very useful for assessment of the area and costs of all bonding within the meta-structure, as well as for comparing the new meta-structure with the classic sandwich panel. It takes into account both the bonding between the facings and the lattice core and bonding between the outer layers and the middle layer of the lattice bars. The parameter Ibf is very sensitive to the thickness of the core - as it is shown in Fig. 4 (see in further text). If Ibf is greater than 2, then the all area and costs of bonding for the meta-structure are higher than the bonding area and costs for the classic sandwich panel.

The next (third) geometric parameter, helpful for the analysis of the new core, is called here the coefficient of impact sensitivity and it is defined as follows,

$$
C i s=\left[n D_{a}+m\left(D_{b}-2 n t\right)\right] 2 t / D_{a} D_{b} \underset{D_{b}=b}{\stackrel{D_{a}=a}{=}} \text { Ric. }
$$

The Cis defines probability of hitting any bar of the grate core by a hard object of size much smaller than the size of the cell $c \times d$. It is noted that within the rectangle of dimensions $D_{a} \times D_{b}=a \times b$, where $D_{a}=a=(m-1) c, D_{b}=b=$ $=(n-1) d, C i s=R i c$. Irrespective of the equality $(C i s=R i c)$, the introduction of Cis parameter seems to be reasonable due to its simple, convincing physical interpretation as the probability of impact of the grate core, and because of high sensitivity of classic sandwich panels to the impact loads. Below, this topic is commented more extensively.

The effects of impact load of sandwich panel with laminate facings and continuous core can be as follows [23]: (1) indentation of facing, (2) debonding between the facing and the core, (3) crushing of the core, (4) delamination between the plies of the laminated facings, (5) matrix cracking, and (6) fiber breakage in the facing. Usually, all the damage modes mentioned above can occur simultaneously. However, the existence and possible crushing of the core seems to be the most cumbersome for the following reasons. Firstly, the area of crushed core is the largest, in particular, it is larger than the debond- 
ing and delamination areas [23]. Secondly, delamination between the plies of laminated facings of a rectangular sandwich panel doesn't need to be dangerous provided that the delaminated facing is not loaded by stretch out-of-plane forces, perpendicular to the plane of delamination [24] and reinforcements of the adjacent, delaminated plies are perpendicular/parallel to the edges of the panel. The first requirement, concerning the out-of-plane stretch loads is satisfied in many sandwich constructions. The latter requirement can also be satisfied. In has been shown in [24-25] that the stress intensity factors $K_{\mathrm{II}}, K_{\mathrm{III}}$ (and the released energies $G_{\mathrm{II}}, G_{\mathrm{III}}$ ) associated with shear stresses between the delaminated plies, along the circumference/edge of the delamination area, are small (close to zero) when the angle $\theta$ between edges of the panel and directions of reinforcement equals either 0 or 90 degrees. Thus, for the cross-plied laminate the delamination is not very dangerous.

Let us note that removing the core material, as it is within the area $(c-2 t) \times$ $\times(d-2 t)$ of the lattice core, removes the problems $2-3$. The cells of dimensions $(c-2 t) \times(d-2 t) \times h$ (see Fig. 1-2) can be filled with a light acoustic foam or sponge not sensitive to impact loads. Moreover, it is noticed that the probability of damage of the meta-structure composed of aluminum facings and the lattice composite core by the impact load is in fact equal to Cis, because damage modes (2)-(6) do not occur in this case, and the aluminum sheet is not so sensitive to impact loads as its laminate counterpart. Due to all abovementioned arguments, application of the lattice core and introduction of Cis seems to be reasonable - see also section 5 .

The usefulness of the above defined parameters, Ric, Ibf and Cis, is also shown in Table 1 which contains comparison between an exemplary core of thickness $h=100 \mathrm{~mm}$ composed of $m \times n=9 \times 9=81$ bars and its continuous counterpart for $D_{a}=a=D_{b}=b=1000 \mathrm{~mm}$.

Table 1.

Comparison of cellular and continuous cores by means of the parameters:

Ric, Cis, Ibf. $h=100 \mathrm{~mm}$

\begin{tabular}{|l|c|c|c|}
\hline \multicolumn{1}{|c|}{ Type of the core } & Ric & Cis & Ibf \\
\hline Continuous & 1 & 1 & 2 \\
\hline $\begin{array}{l}\text { Composed of bars, } c=d, \\
2 t / c=0.2, D_{a}=a, D_{b}=b\end{array}$ & 0.36 & 0.36 & $\sim 4.67$ \\
\hline
\end{tabular}

The data collected in Table 1 show that the cellular core, composed of the three-layer bars, as it is shown in Fig. 2, is much less sensitive to impact than the continuous core. Unfortunately, much more glue is necessary to connect all the stiff layers with compliant layers within the cellular core and to connect the core with the facings of the meta-structure than in the case of the classic panel 
with continuous core. The parameter $I b f=4.67$ for the grate core is more than two times higher than for the classic core.

In Fig 3, the Ibf parameter is shown in the domain of $t_{2}$ for $t_{1}=1.5 \mathrm{~mm}$ and $h=100 \mathrm{~mm}$. The results have been obtained under the assumption of constant values of another parameters occurring in (4-7).

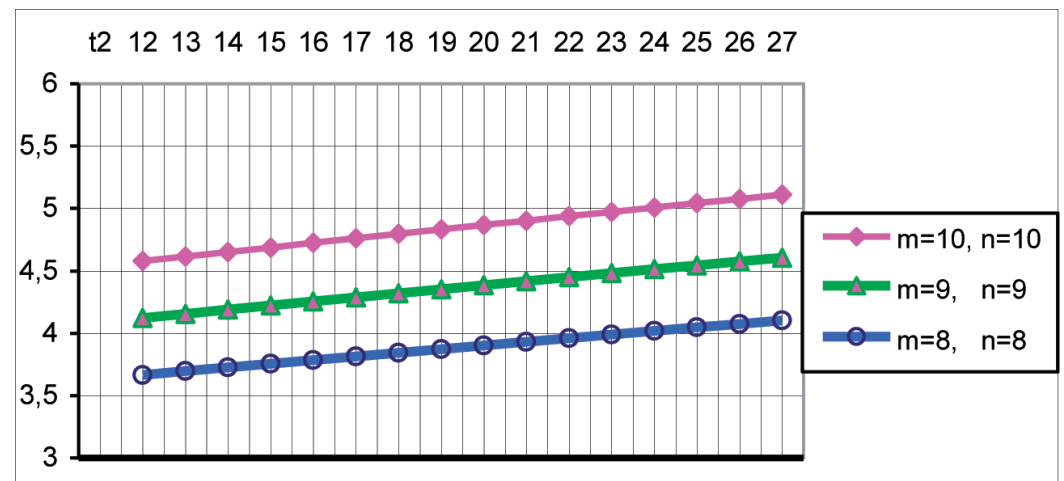

Fig. 3. $I b f$ versus $t_{2}$ for assumed: $a_{t}=1000 \mathrm{~mm}, b_{t}=1000 \mathrm{~mm}, t_{1}=1.5 \mathrm{~mm}$

In Fig 4, the Ibf parameter is shown in the domain of $t_{2}$ for $t_{1}=1 \mathrm{~mm}$, $h=100 \mathrm{~mm}$ and $h=30 \mathrm{~mm}$. The results have been obtained under the assumption of constant values of another parameters occurring in (4-7).

t2 12131415161718192021222324252627

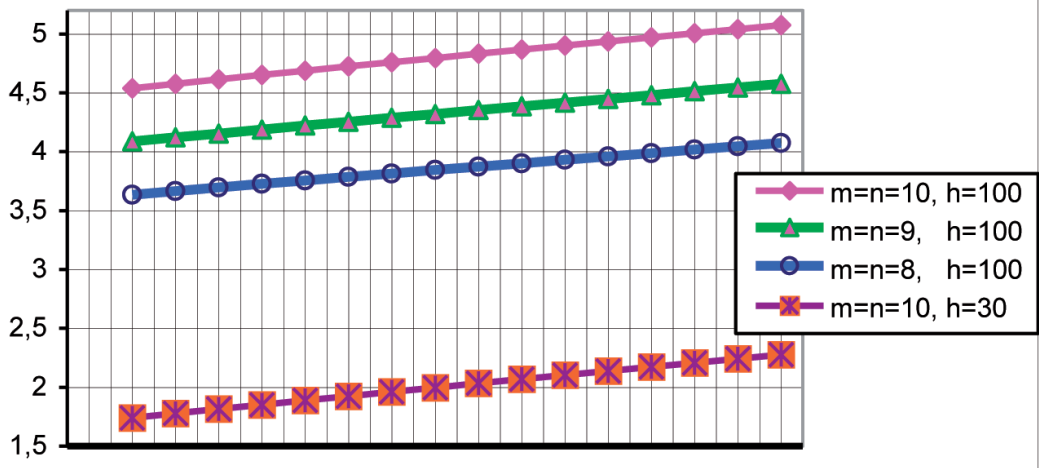

Fig. 4. Ibf versus $t_{2}$ for assumed: $a_{t}=1000 \mathrm{~mm}, b_{t}=1000 \mathrm{~mm}$, and $t_{1}=1 \mathrm{~mm}$

From the data in Figs 3, 4, one can conclude that the interlayer bonding factor is weakly dependent on (almost independent of) the thickness $t_{1}$ of outer layers of the bars and it is very sensitive to the thickness $h$.

In Fig. 5, the Cis parameter is shown in the domain of $t_{2}$ for $t_{1}=1.5 \mathrm{~mm}$. The results have been obtained under assumption of constant values of other parameters occurring in (8). 
t2 12131415161718192021222324252627

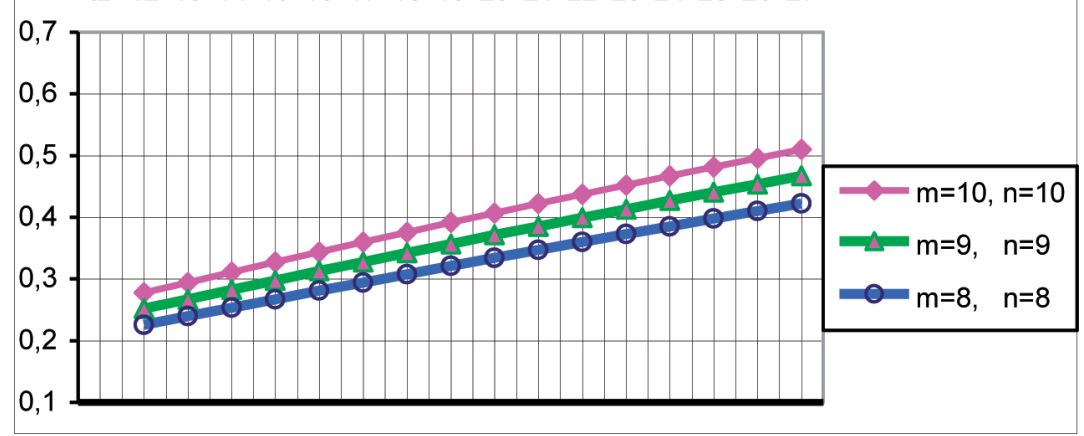

Fig. 5. Cis versus $t_{2}$ for assumed: $a_{t}=1000 \mathrm{~mm}, b_{t}=1000 \mathrm{~mm}$, and $t_{1}=1.5 \mathrm{~mm}$

In Fig. 6, the Cis parameter is shown in the domain of $t_{2}$ for $t_{1}=1 \mathrm{~mm}$. The results have been obtained under the assumption of constant values of other parameters occurring in (8).

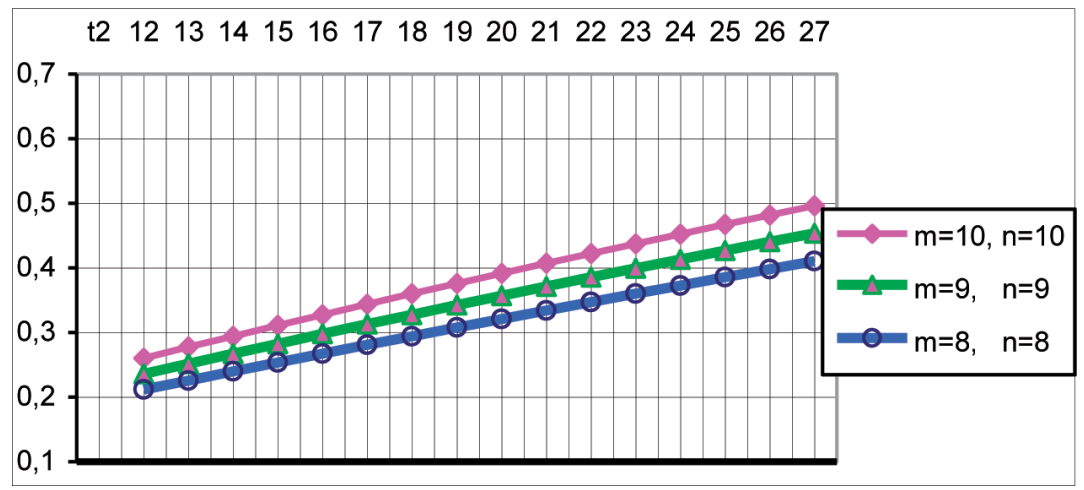

Fig. 6. Cis versus $t_{2}$ for assumed: $a_{t}=1000 \mathrm{~mm}, b_{t}=1000 \mathrm{~mm}$, and $t_{1}=1 \mathrm{~mm}$

Comparing data in Figs 5, 6 one can see that the coefficient of impact sensitivity is weakly dependent on (almost independent of) the thickness $t_{1}$ of outer layers of the bars.

\section{Condition of equality of the masses of continuous core and the grid one}

To obtain the condition, the following parameters, i.e., the mass of the continuum foam core $\left(m_{c f c}\right)$, the mass of facings of the bars in the grid core $\left(m_{f b l}\right)$, and the mass of foam layers of the bars in the grid core $\left(m_{f}\right)$ have to be first obtained, as follows, 


$$
\begin{gathered}
m_{c f c}=D_{a} D_{b} h \rho_{c f c}, \\
m_{f b l}=\left[n D_{a}+m D_{b}-2 m n t\right] 2 t_{1} h \rho_{f b l}=\left[n\left(D_{a}-m t\right)+m\left(D_{b}-n t\right)\right] 2 t_{1} h \rho_{f b l}, \\
m_{f l}=\left[n\left(D_{a}-m t\right)+m\left(D_{b}-n t\right)\right] t_{2} h \rho_{f l}=m_{f b l} \frac{t_{2}}{2 t_{1}} \frac{\rho_{f l}}{\rho_{f b l}} .
\end{gathered}
$$

If the mass of the grid core is smaller than or equal to the mass of the continuus core, the following inequality must be satisfied,

$$
\begin{gathered}
m_{f b l}+m_{f l} \leq m_{c f c} \equiv m_{f b l}\left(1+\frac{t_{2}}{2 t_{1}} \frac{\rho_{f l}}{\rho_{b f l}}\right) \leq m_{c f c} \\
{\left[n\left(D_{a}-m t\right)+m\left(D_{b}-n t\right)\right] 2 t_{1} h \rho_{f b l} \leq D_{a} D_{b} h \rho_{c f c}-\left[n\left(D_{a}-m t\right)+\right.} \\
\left.+m\left(D_{b}-n t\right)\right] t_{2} h \rho_{f l} .
\end{gathered}
$$

Directly from (11) one obtains,

$$
\begin{aligned}
& \rho_{f l}=\rho_{c f c} \Leftrightarrow \frac{\rho_{f b l}}{\rho_{c f c}} \leq \frac{D_{a} D_{b}-\left[n\left(D_{a}-m t\right)+m\left(D_{b}-n t\right)\right] t_{2}}{\left[n\left(D_{a}-m t\right)+m\left(D_{b}-n t\right)\right] 2 t_{1}}, \\
& \rho_{f l}=\rho_{c f c} \Leftrightarrow \frac{\rho_{f b l}}{\rho_{c f c}} \underset{D_{b}=b_{t}}{\leq} \frac{D_{t} b_{t}-\left[n\left(a_{t}-m t\right)+m\left(b_{t}-n t\right)\right] t_{2}}{\left[n\left(a_{t}-m t\right)+m\left(b_{t}-n t\right)\right] 2 t_{1}} .
\end{aligned}
$$

After using the equalities, resulting from (3) and (7),

$$
\begin{gathered}
a_{t}=m_{1} c+2 t=(m-1) c+2 t, \\
b_{t}=m_{2} d+2 t=(n-1) d+2 t \stackrel{d=c}{=}(n-1) c+2 t, \quad m, n=2,3, \ldots,
\end{gathered}
$$

the following expression for the ratio $\rho_{f b l} / \rho_{c f c}$ is obtained from (12b),

$$
\begin{aligned}
& \rho_{f l}=\rho_{c f c} \Leftrightarrow \frac{\rho_{f b l}}{\rho_{c f c}} \leq \\
& \leq \frac{[(m-1) c+2 t][(n-1) d+2 t]-\{n[(m-1) c-(m-2) t]+m[(n-1) d-(n-2) t]\} t_{2}}{\{n[(m-1) c-(m-2) t)]+m[(n-1) d-(n-2) t]\} 2 t_{1}} .
\end{aligned}
$$

In Table 2 one can see dependence of the ratio $\rho_{f b l} / \rho_{c f c}$ on $t_{2}$ under the assumption of constant values of other parameters occurring in (12). 
Table 2 .

Ratio $\rho_{f b l} / \rho_{c f c}$ versus $t_{2}$ for assumed parameters: $a_{t}=1000 \mathrm{~mm}, b_{t}=1000 \mathrm{~mm}$, and $t_{1}=1.5 \mathrm{~mm}$

\begin{tabular}{|c|c|c|c|c|c|c|c|c|c|c|c|c|c|c|c|c|}
\hline$t_{2} \mathrm{~mm}$ & 12 & 13 & 14 & 15 & 16 & 17 & 18 & 19 & 20 & 21 & 22 & 23 & 24 & 25 & 26 & 27 \\
\hline$m=10$ & 14.0 & 13.8 & 13.6 & 13.3 & 13.1 & 12.9 & 12.6 & 12.4 & 12.2 & 11.9 & 11.7 & 11.5 & 11.3 & 11.1 & 10.8 & 10.6 \\
\hline$m=9$ & 15.9 & 15.6 & 15.4 & 15.2 & 14.9 & 14.7 & 14.5 & 14.2 & 14.0 & 13.8 & 13.5 & 13.3 & 13.1 & 12.9 & 12.6 & 12.4 \\
\hline$m=8$ & 18.2 & 17.9 & 17.7 & 17.5 & 17.2 & 17.0 & 16.7 & 16.7 & 16.3 & 16.1 & 15.8 & 15.6 & 15.4 & 15.1 & 14.9 & 14.7 \\
\hline
\end{tabular}

The data from Table 2 are presented in Fig. 7.

t2 12131415161718192021222324252627

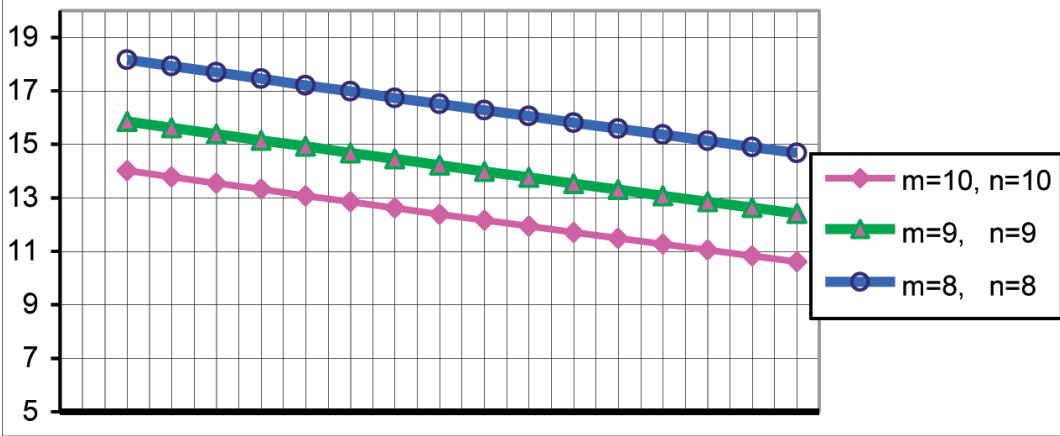

Fig. 7. Ratio $\rho_{f b l} / \rho_{c f c}$ versus $t_{2}$ for assumed parameters: $a_{t}=1000 \mathrm{~mm}, b_{t}=1000 \mathrm{~mm}$, and $t_{1}=1.5 \mathrm{~mm}$

In Fig. 8, there is shown the ratio $\rho_{f b l} / \rho_{c f c}$ versus $t_{2}$ for $t_{1}=1 \mathrm{~mm}$.

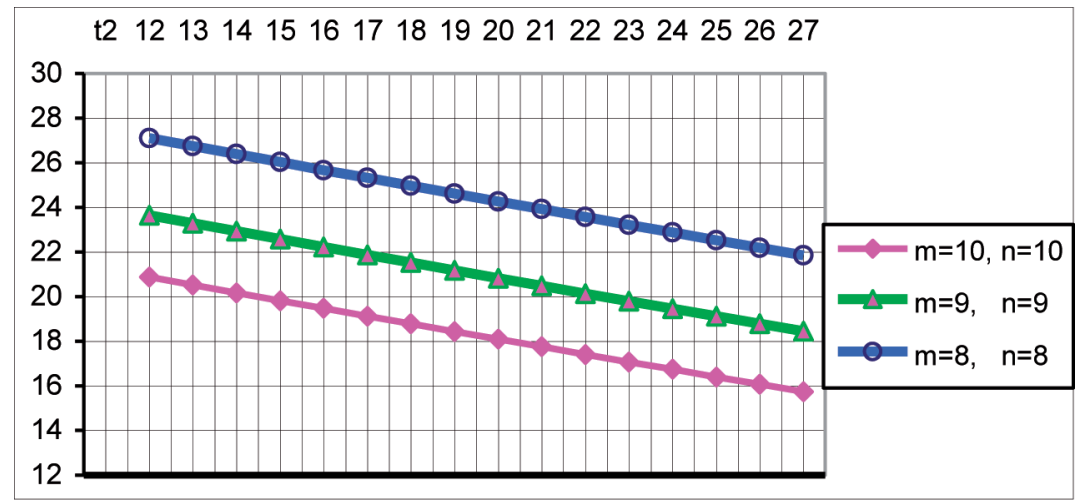

Fig. 8. Ratio $\rho_{f b l} / \rho_{c f c}$ versus $t_{2}$ for assumed: $a_{t}=1000 \mathrm{~mm}, b_{t}=1000 \mathrm{~mm}$, and $t_{1}=1 \mathrm{~mm}$

Comparing data in Figs 7, 8 one can observe that the ratio $\rho_{f b l} / \rho_{c f c}$ is very sensitive to the thickness $t_{1}$ of outer layers of the bars and it increases with decreasing $t_{1}$. 
The formal analysis (see e.g. chart in Fig. 8) indicates that, applying available materials, we are able to build the lattice core composed of three-layer bars, which is not heavier than the classic continuous core made of a polymer foam. For instance, assuming that density of the foam equals to $70 \mathrm{~kg} / \mathrm{m}^{3}$, $t_{1}=1 \mathrm{~mm}, t_{2}=18 \mathrm{~mm}$, and $m=n=8$, one obtains from the chart in Fig. 8 the density of the outer layers of the bars $\left(\rho_{f b l}\right)$ equal to $70 \cdot 25=1750 \mathrm{~kg} / \mathrm{m}^{3}$. If density of the outer layers of the bars is less than $1750 \mathrm{~kg} / \mathrm{m}^{3}$, then the lattice core will be lighter than its continuous counterpart made of the foam of density equal to $70 \mathrm{~kg} / \mathrm{m}^{3}$. The dimensions of the cells $c \times d$ in the case are $c=d=140 \mathrm{~mm}$.

The purpose of the geometric analysis in sections 3-5 is to show some properties, as well as the possibilities and limitations, of making the new lattice core, which would not be heavier than a conventional core of polyurethane foam. What's more, the Ric, Cis and Ibf parameters can be useful for preliminary design of the meta-structure. The choice of the basic parameters, $t_{1}, t_{2}, h, \rho_{1}, \rho_{2}, m$ and $n$ is the first step of the design process. It can be done by means of the graphs, as shown in sections $4-5$. The basic principle of the design process is as follows: to obtain as small values of Cis and Ibf parameters and as high value of the ratio $\rho_{1} / \rho_{2} \equiv \rho_{f b l} / \rho_{c f c}$ as possible, and to satisfy the design criteria for the meta-structure. The graphs such as 3-4, 5-6 and 7-8 show how the complex parameters (Cis, Ibf and $\rho_{1} / \rho_{2}$ ) depend on $t_{1}, t_{2}, h, m$, $n$ and enable us to make a reasonable, compromise choice (assumption) of the basic parameters.

Thus, assuming $t_{1}, m, n$ and Cis one can obtain, from Fig. 5-6, the thickness $t_{2}$. Then, assuming $\rho_{2} \equiv \rho_{c f c}$ and using the graphs as in Fig. 7-8, one can obtain the ratio $\rho_{1} / \rho_{2} \equiv \rho_{f b l} / \rho_{c f c}$ and the density $\rho_{1} \equiv \rho_{f b l}$. Upon the basis of these data, and using the graphs as in Fig. 3-4, one can select the parameter $h$. After selecting the basic parameters $\left(m, n, t_{1}, t_{2}, h, \rho_{1}, \rho_{2}\right)$ the designer has to check some design criteria, strength, stiffness and cost, e.g. using the commercial FEM software.

\section{Meta-structure investigated experimentally}

The core of the meta-structure investigated experimentally is shown in Fig. 9.

The core in Fig. 9 has been built of three bars of length $1200 \mathrm{~mm}$ $\left(D_{a}=1.2 \mathrm{~m}\right)$ and twelve bars of length $230 \mathrm{~mm},\left(D_{b}=0.23 \mathrm{~m}\right)$. To decrease its weight, two outer bars of length $D_{a}$ have been composed of two layers. One of the layers ( $2 \mathrm{~mm}$ thick) has been made of fiberboard and the latter $(16 \mathrm{~mm}$ thick) has been made of PIR foam of density $30 \mathrm{~kg} / \mathrm{m}^{3}$. The inner bar of length 


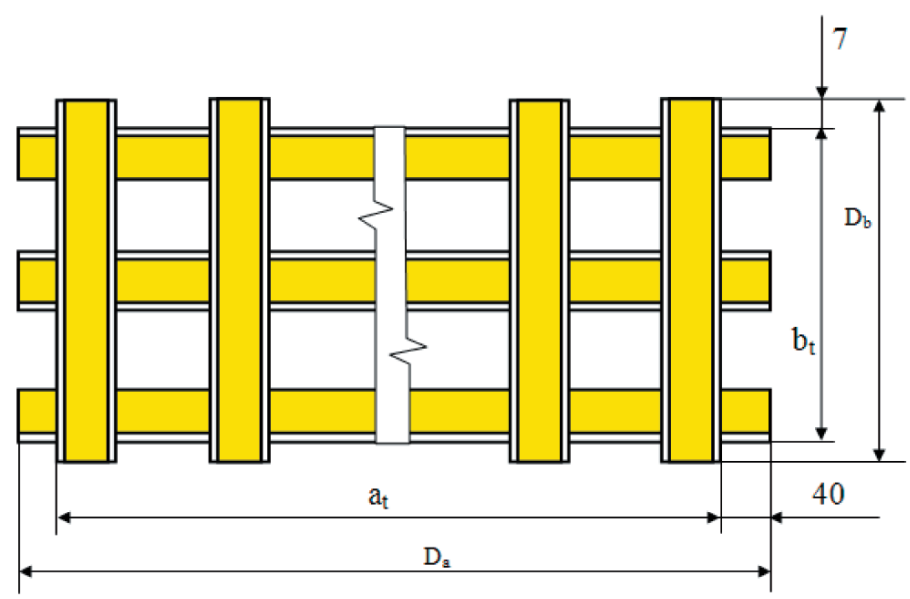

Fig. 9. Core of the meta-structure investigated experimentally - with two-layer outer bars and three-layer inner bar of length $D_{a}$

$D_{a}$ consists of three layers. Also, all bars of length $D_{b}$ consist of three layers. Outer layers of the three-layer bars are made of the fiberboard, and the middle layers are cut from the PIR foam. These materials were selected because they were readily availabile. The thicknesses of layers of the three-layer bars are $t_{1}=2 \mathrm{~mm}$ and $t_{2}=16 \mathrm{~mm}$, hence $2 t=2 t_{1}+t_{2}=20 \mathrm{~mm}-$ see Fig. 2 . The thickness of the core is $h=30 \mathrm{~mm}$ - see Fig. 2. The dimensions of the cells $c \times d$ (see Fig. 2) are $100 \mathrm{~mm} \times 100 \mathrm{~mm}$. The three-layer meta-structure, studied experimentally, has been composed of the core shown in Fig. 9, and two facings of fiberboard glued to the core. The dimensions of the facings are $1.2 \mathrm{~m} \times 0.23 \mathrm{~m} \times 0.002 \mathrm{~m}$. Hence, total thickness of the metastructure is $H=h+2 t_{f}=34 \mathrm{~mm}$, where $t_{f}$ denotes the thickness of facing. All the grid core data are collected in Table 3 .

Table 3.

The geometrical parameters of core of the meta-structure, in milimeters

\begin{tabular}{|c|c|c|c|c|c|c|c|c|c|}
\hline$D_{a}$ & $D_{b}$ & $a_{t}$ & $b_{t}$ & $c$ & $d$ & $h$ & $t_{1}$ & $t_{2}$ & $2 t$ \\
\hline 1200 & 230 & 1120 & 216 & 100 & 100 & 30 & 2 & 16 & 20 \\
\hline
\end{tabular}

It is noted that the consequence of the presence of the two longitudinal two-layer bars in the grid core shown in Fig. 9 are the following expressions for $m_{c f c}, m_{f b l}, m_{f l}$, and $\rho_{f b l} / \rho_{c f c}$, defined in section 5,

$$
\begin{gathered}
m_{c f c}=D_{a} D_{b} h \rho_{c f c}, \\
m_{f b l}=\left[\left(D_{a}-m t\right)(n-1)+m\left(D_{b}-n t+t_{1}\right)\right] 2 t_{1} h \rho_{f b l},
\end{gathered}
$$




$$
\begin{gathered}
m_{f l}=\left[n\left(D_{a}-m t\right)+m\left(D_{b}-n t+t_{1}\right)\right] t_{2} h \rho_{f l}, \\
\rho_{f l}=\rho_{c f c} \Leftrightarrow \frac{\rho_{f b l}}{\rho_{c f c}}=\frac{D_{a} D_{b}-\left[n\left(D_{a}-m t\right)+m\left(D_{b}-n t+t_{1}\right)\right] t_{2}}{\left[\left(D_{a}-m t\right)(n-1)+m\left(D_{b}-n t+t_{1}\right)\right] 2 t_{1}} .
\end{gathered}
$$

The dependence of the ratio $\rho_{f b l} / \rho_{c f c}$, expressed by (18), versus $t_{2}$ for different $t_{1}$ is shown in Fig. 10. One can see that this ratio is very sensitive to the thickness $t_{1}$ of the outer layers of the three-layer bars of the grid core. The ratio $\rho_{f b l} / \rho_{c f c}$ increases with decreasing $t_{1}$.

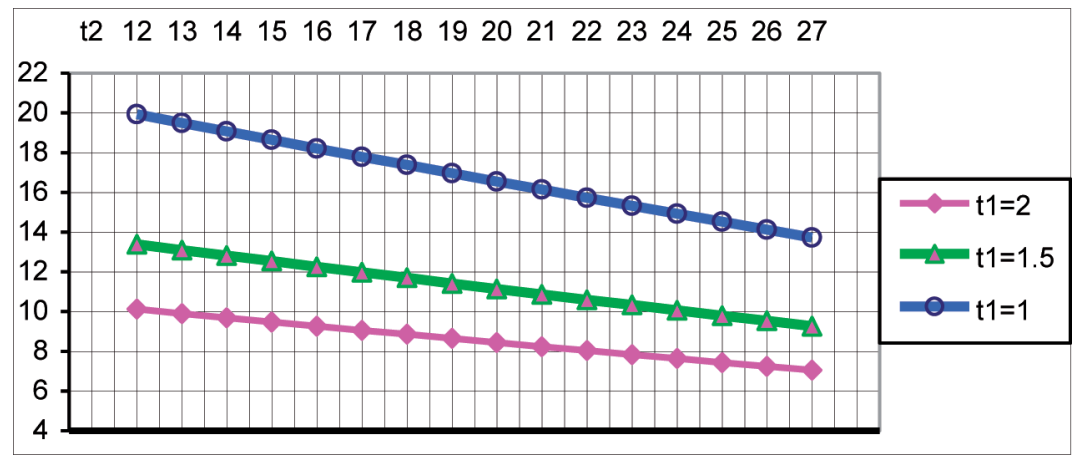

Fig. 10. The ratio $\rho_{f b l} / \rho_{c f c}$ versus $t_{2}$ for the meta-structure investigated experimentally: $a_{t}=1120 \mathrm{~mm}, b_{t}=216 \mathrm{~mm}, m=12, n=3$, and $t_{1}=2,1.5$ and $1 \mathrm{~mm}$, respectively

Before presentation of the experimental assessement of the sandwich meta-structure composed of the outer layers and the novel core shown in Fig. 2, 9, an analytic consideration is presented here to better hightlight its mechanical properties. Let us first note that the arrangement of the three-layer bars, such as shown in Fig. 2, 9, allows us to obtain more rigid connection of the outer layers of the meta-structure. It is possible owing to the fact that the outer layers of the three-layer bars are made of a material of high rigidity, whereas the middle layer (of a soft material) acts as a stabilizer for the outer layers of the bars.

It is well known (see e.g. [26]) that sandwich beam can be treated as a homogeneous I-beam with flanges of width $b_{f}$ and web of width $b_{w}$, whereas $b_{w}$ is defined as follows [26],

$$
b_{w}=b_{f} E_{c} / E_{f} \stackrel{b_{f}=h}{=} h E_{c} / E_{f} .
$$

$E_{c}, E_{f}$ in (19) are the Young's moduli of the core and facings, respectively. $E_{f}$ is the Youngs's modulus of a homogeneous I-beam which is functionally 
equivalent to the sandwich one. If the I-beam is rotated by 90 degrees, then we have the H-beam which is a model of the three-layer bar, which in turn is a part of the grid shown in Fig. 2, 9. An illustration to the above comment is shown in the diagram:
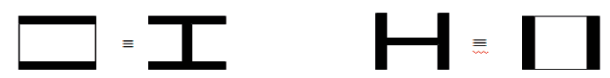

The dimensions of the I-beam (and consequently those of the H-beam) can be obtained directly from Fig. 2 and formula (19). It is seen in Fig. 2 that dimensions of outer layers of the three-layer bars are $t_{1} \times h$ and dimensions of the web of the I-beam (and H-beam) are $b_{w} \times t_{2}$, whereas $b_{w}$ is defined by (19). Below we compare the moments of inertia of an I-beam and an H-beam having the same sectional dimensions. The moment of inertia of the I-beam can be defined as follows,

$$
\begin{gathered}
I_{I}=\frac{h\left(t_{2}+2 t_{1}\right)^{3}}{12}-\frac{h t_{2}^{3}}{12}+\frac{b_{w} t_{2}^{3}}{12}, \\
I_{I}=\frac{h t_{2}^{3}}{12}\left[\left(\frac{t_{2}+2 t_{1}}{t_{2}}\right)^{3}-1+E_{c} / E_{f}\right] \equiv \\
\equiv \frac{t_{1} h^{3}}{12} \frac{t_{2}}{t_{1}}\left(\frac{t_{2}}{h}\right)^{2}\left[\left(\frac{t_{2}+2 t_{1}}{t_{2}}\right)^{3}-1+E_{c} / E_{f}\right],
\end{gathered}
$$

Assuming that $t_{2} / t_{1}=16$ or $t_{2} / t_{1}=8$, and $E_{c} / E_{f}=0.01$, one obtains,

$$
\begin{aligned}
& I_{I}=\frac{t_{1} h^{3}}{12} 6.94\left(\frac{t_{2}}{h}\right)^{2}=\frac{t_{1} h^{3}}{6} 3.47\left(\frac{t_{2}}{h}\right)^{2} \underset{t_{2}=16 t_{1}}{\stackrel{h=2 t_{2}}{\cong}} 0.87 \frac{t_{1} h^{3}}{6} \\
& I_{I}=\frac{t_{1} h^{3}}{12} 7.7\left(\frac{t_{2}}{h}\right)^{2}=\frac{t_{1} h^{3}}{6} 3.85\left(\frac{t_{2}}{h}\right)^{2} \stackrel{\substack{h=2 t_{2} \\
t_{2}=8 t_{1}}}{\cong} 0.96 \frac{t_{1} h^{3}}{6}
\end{aligned}
$$

The moment of inertia for the H-beam is as follows,

$$
I_{H}=\frac{t_{1} h^{3}}{12}\left[2+\left(b_{w} / h\right)^{3}\left(t_{2} / t_{1}\right)\right] \equiv \frac{t_{1} h^{3}}{12}\left[2+\left(E_{c} / E_{f}\right)^{3}\left(t_{2} / t_{1}\right)\right] \cong \frac{t_{1} h^{3}}{6} .
$$

Comparing (20c)-(20d) and (21) one can see that, for the realistic ratios, $t_{2} / t_{1} \geq 8, E_{c} / E_{f} \leq 0.01$ and $t_{2} / h \leq 0.5$, the inertia moment $I_{H}$ is greater than $I_{I}$. 
Thus, the realistic novel H-core proposed in this paper should be stiffer than the I-core of the same dimensions. Such a conclusion is consistent with the experimental results presented in the work.

This conclusion applies to the situation where the I-beam is just the $\mathrm{H}$-beam rotated by 90 degrees and does not apply in the cases where dimensions of the cross-section of the I-beam (which is counterpart of the sandwich beam) are different than dimensions of $\mathrm{H}$-beam.

\section{Experimental set-up and results}

Both the meta-structure and the classic sandwich structure have been investigated by means of the experimental set-up shown in Fig. 11. The classical sandwich structure, counterpart of the meta-structure, has been made of three continuous layers. The middle layer was cut from the PIR foam of density $30 \mathrm{~kg} / \mathrm{m}^{3}$ is of dimensions $1.2 \mathrm{~m} \times 0.23 \mathrm{~m} \times 0.03 \mathrm{~m}$. The fibreboard facings had dimensions $1.2 \mathrm{~m} \times 0.23 \mathrm{~m} \times 0.002 \mathrm{~m}$. The continuous core was glued to the facings. The main purpose of these experimental studies was to answer the question, which of these two structures shows greater flexural stiffness.

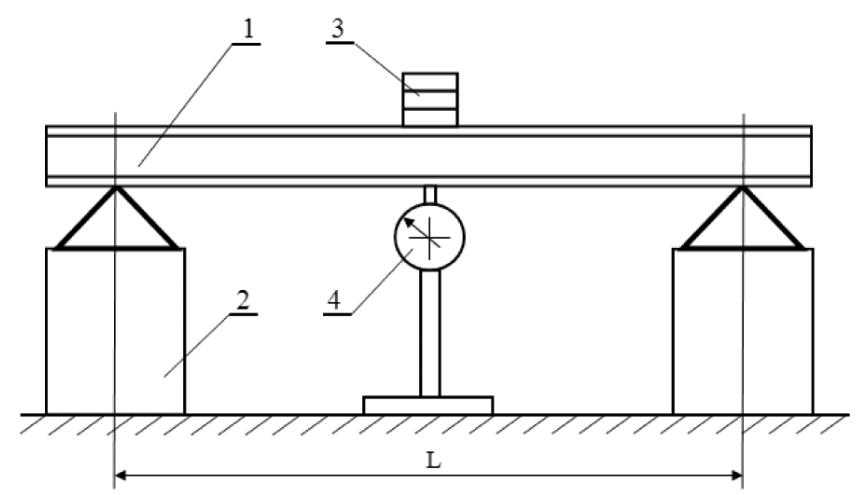

Fig. 11. Experimental set-up: 1 - sandwich structure, 2 - support of the structure, 3 - loading, 4 - mechanical indicator for measurement of deflections

Each of the structures was loaded by means of pieces of thick steel sheet of equal mass $m=0.35 \mathrm{~kg}$ (equivalent to the weight of $Q=3.46 \mathrm{~N}$ ) and the maximum deflection in the middle of span $L$ was measured by means of the mechanical indicator - see Fig. 11. The loadings equal to $n Q, n=1 \div 6-$ see Figs 12-17, and the corresponding measurements for each length $L$ were repeated 6 times in two series. Three measurements were done in each of the series. In Figs. 12-17, maximum deflections of the structures are shown. 


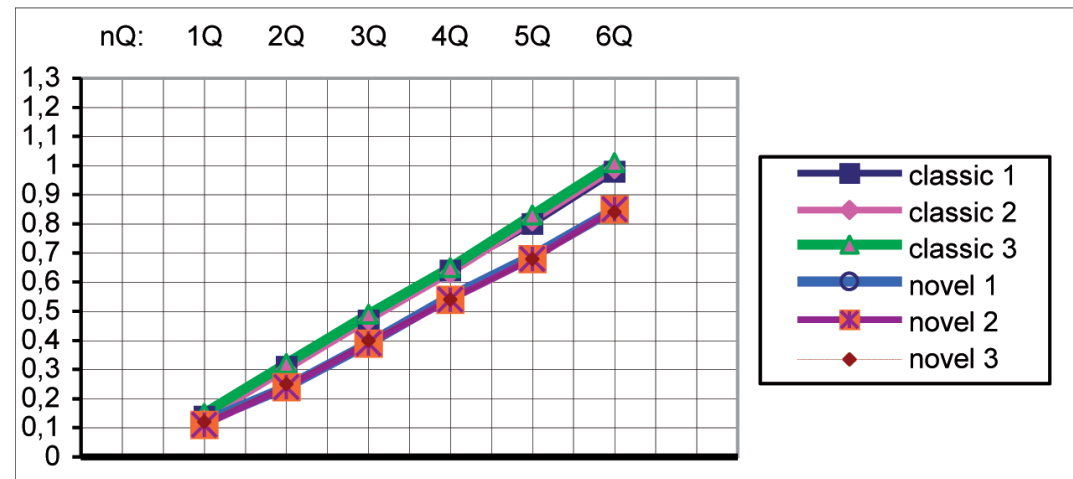

Fig. 12. Measured maximum deflections ( $\mathrm{mm}$ ) of the structures for $L=1.0 \mathrm{~m}, L / H=29.4$, series 1

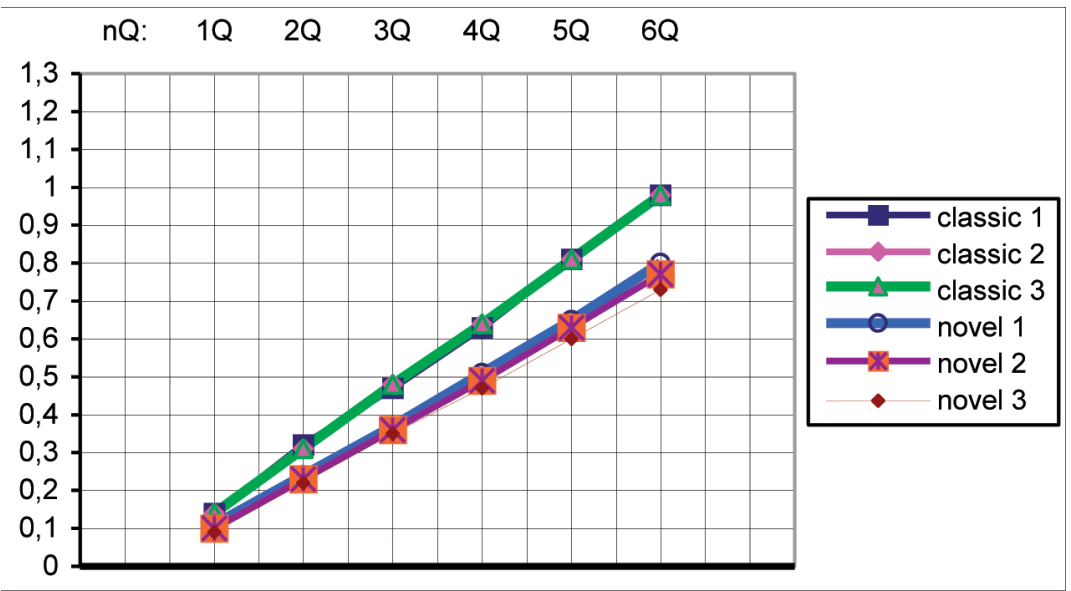

Fig. 13. Measured maximum deflections (mm) of the structures for $L=1.0 \mathrm{~m}, L / H=29.4$, series 2

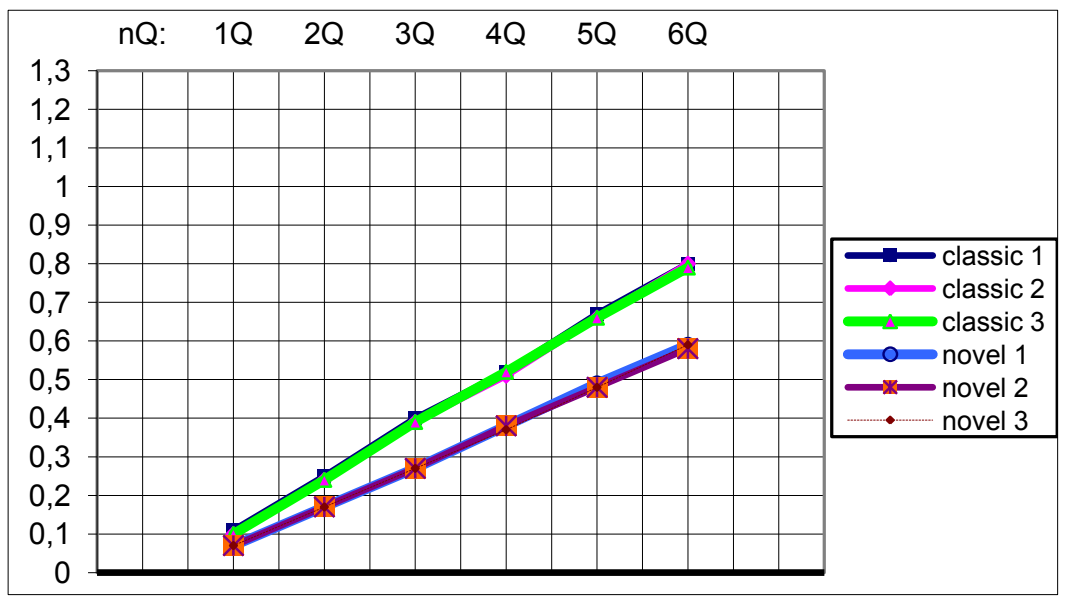

Fig. 14. Measured maximum deflections (mm) of the structures for $L=0.9 \mathrm{~m}, L / H=26.5$, series 1 


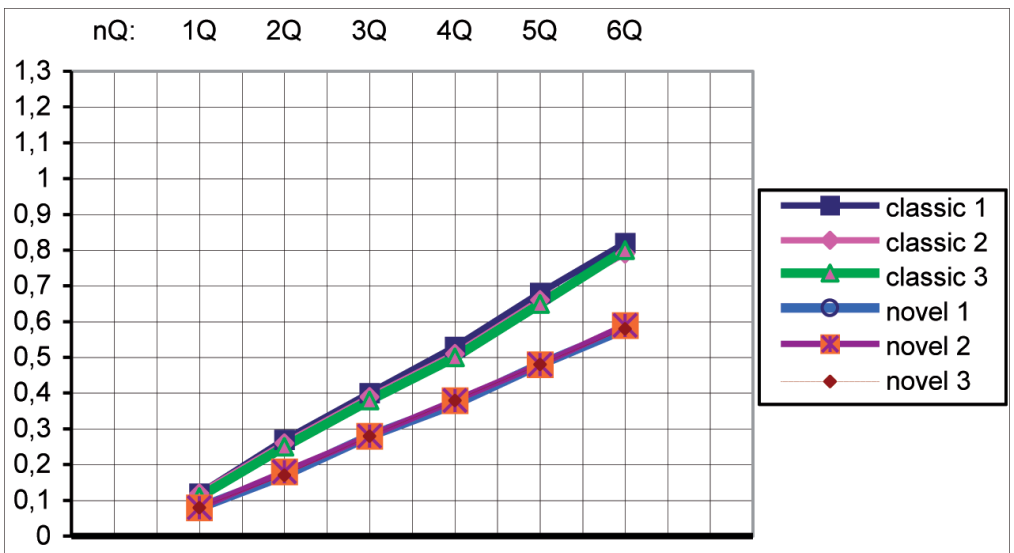

Fig. 15. Measured maximum deflections (mm) of the structures for $L=0.9 \mathrm{~m}, L / H=26.5$, series 2

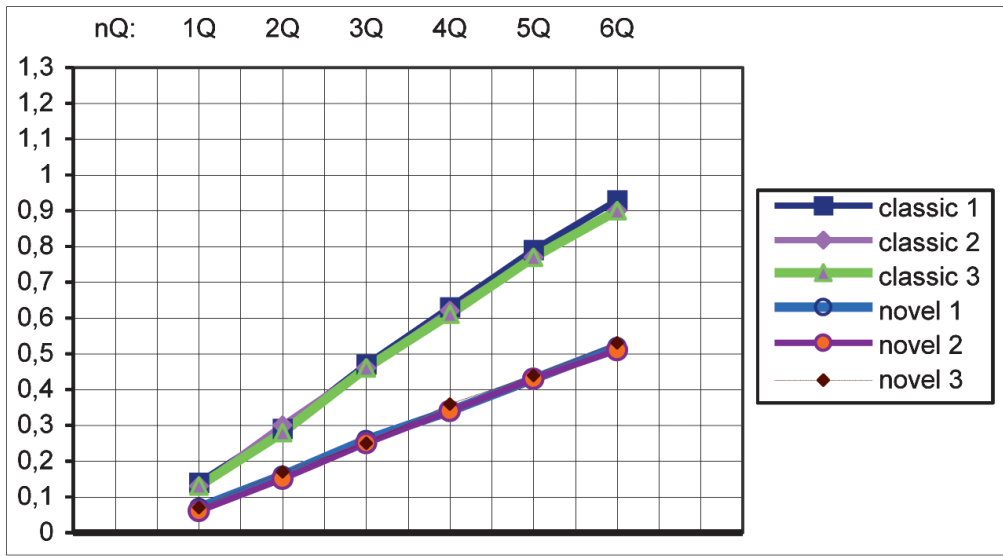

Fig. 16. Measured maximum deflections (mm) of the structures for $L=0.8 \mathrm{~m}, L / H=23.5$, series 1

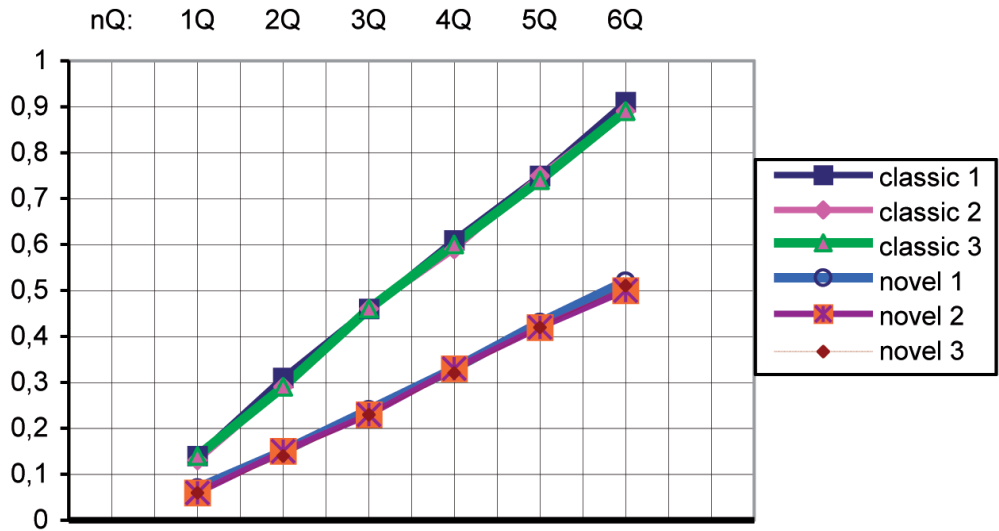

Fig. 17. Measured maximum deflections (mm) of the structures for $L=0.8 \mathrm{~m}, L / H=23.5$, series 2 
It is seen in Figs 12-17 that the deflections of the sandwich meta-structure, for the assumed loading, are lower than the deflections of the classic sandwich structure. It means that flexural stiffness of the meta-structure is higher than flexural stiffness of the classic structure. Moreover, the difference between the deflections of the classic structure and the meta-structure, $U_{c m}=U_{c}-U_{m}$, is dependent on the span length $L$ and increases with decreasing $L$. As expected, deflections of the structures in Figs 12-17 are (approximately) proportional to the loading.

In regards to the static response of the meta-structure, it is reasonable to distinguish the overall and local responses. One may expect that the overall response of the meta structure is lower than, but spatially similar as the response of the classic sandwich structure. Such an opinion is justified by the fact of application, by different authors, of the same mathematical models for the sandwich panels with corrugated core [13] and sandwich panels with continuous cores [26]. A similar approach, supporting the above opinion, is applied in paper [27] devoted to vibration analysis of homogeneous plate which is stiffened on one side by a homogeneous grate shown in Fig. 1. However, the local responses of the meta-structure, in particular within the cells of dimensions $(c-2 t) \times(d-2 t)-$ see Fig. 1 and local responses of its classic, three-layer counterpart are expected to be different. It is because the facings of the meta-structure are not supported by the core within the rectangles $(c-2 t) \times(d-2 t)$, as in the case of the classic, three-layer panel.

\section{Conclusions}

Geometrical analysis, by means of the parameters introduced in sections 2 and 4, shows that the new lattice core, composed of the three-layer bars, is much less sensitive to impact than the continuous core. However, the grid core is much more laborious to be made, and therefore more expensive (for its higher thicknesses) than its continuous counterpart.

It has been shown that there is the possibility of making, out of available materials, the lattice core consisting of three-layer bars with the weight not higher than the weight of the continuous core.

The experimental results show that stiffness of the lattice core made of the three-layer bars is higher than the stiffness of the continuous core. The difference between the stiffnesses increases with the decrease of span of the investigated structure. 


\section{REFERENCES}

[1] Wang X., Starlinger A., Dean R.J. and Wieschermannk J.: The application of sandwich components in the design of the new transrapid maglev TR08 vehicles, Proceedings of the $5^{\text {th }}$ Int. Confer. on Sandwich Construction, ETH Zurich, Switzerland, Sept. 2000, Vol 2, 539-549.

[2] Wu H.-C., Mu B., Warnermuende K.: Failure analysis of FRP sandwich bus panels by finite element method, Coposites, Part B: engineering, 2003, p. 51.

[3] Herrmann A.S., Zahlen P.C. and Zuardy I.: Sandwich structures technology in commercial aviation, Proceedings of the $7^{\text {th }}$ International Conference on Sandwich Construction, Aalborg University, Denmark, August 2005, pp. 13-26.

[4] Paolozzi A. and Peroni I.: Response of aerospace sandwich panels to launch acoustic environment, Journal of Sound and Vibration, 1996, p. 1.

[5] Thamburaj P. and Sun J.Q.: Effect of material anisotropy on the sound and vibration transmission loss of sandwich aircraft structures, Journal of Sandwich Structures and Materials, 1999, 1, pp. 76-92.

[6] Sorokin S.V.: Analysis of wave propagation in sandwich plates with and without heavy fluid loading, Journal of Sound and Vibration, 2004, 271, pp. 1039-1062.

[7] Renji K.: Sound transmission loss of unbounded panels in bending vibration considering transverse shear deformation, Journal of Sound and Vibration, 2005, 283, pp. 478-486.

[8] T. Wang T., Sokolinsky V.S., Rajaram S., S.R. Nutt S.R.: Assessment of sandwich models for the prediction of sound transmission loss in unidirectional sandwich panels, Applied Acoustics, 2005, 66, pp. 245-262.

[9] Karczmarzyk S.: Local model of plane acoustic waves propagation in multilayered infinite sandwich structures, Archives of Mechanics, 2011, 63, pp. 573-598.

[10] Muc A., Nogowczyk R.: Formy zniszczenia konstrukcji sandwiczowych z okładzinami wykonanymi z kompozytów, Kompozyty (Composites), 2005, 5, pp. 31-35.

[11] Burlayenko V.N., Sadowski T.: Influence of skin/core debonding on free vibration behavior of foam and honeycomb cored sandwich plates, International Journal of Non-Linear Mechanics, 2010, 45, pp. 959-968.

[12] Shiah Y.C. and Huang J.H.: Characterization of the effective elastic modulus of an integrated sandwich composite, Journal of Composite Materials, 2003 - 1131pp.

[13] Lok T.S., Cheng Q.H.: Elastic deflection of thin-walled sandwich panel, Journal of Sandwich Structures and Materials, 1999, 1, pp. 279-298.

[14] Fung T.C., Tan K.H. and Lok T.S.: Shear stiffness $D_{Q y}$ for C-core sandwich panels, Journal of Structural Engineering, 1996, pp. 958-966.

[15] Taczała M., Banasiak W.: Buckling of I-core sandwich panel, Journal of Theoretical and Applied Mechanics, 2004, 42, pp. 335-348.

[16] Karczmarzyk S.: Sandwich panel construction/Panel konstrukcyjny typu sandwich, Patent Application No. P-408828, 2014.

[17] Pflug J., Verpoest I., Vandepitte D.: Folded honeycomb cardboard and core material for structural applications, Proc. $5^{\text {th }}$ Int. Conf. on Sandwich Constr., Zurich, Switzerland, Sept. 2000, 361-372.

[18] Vivolo M., Pluymers B., Vandepitte D., Desmet W.: An experimental-numerical study on the vibro-acoustic characterization of honeycomb lightweight panels, Proc. ISMA 2010, KU Leuven, 2197-2211.

[19] Shiah Y.C. and Huang J.H.: Characterization of the Effective Elastic Modulus of an Integrated Sandwich Composite, Journal of Composite Materials, 2002, 37, 1131-1147.

[20] Sypeck D.J.: Cellular Truss Core Sandwich Structures, Applied Comp. Materials, 2005, 12, 229-246.

[21] Best Practice Guide for Sandwich Structures in Marine Applications, European Commission Contract No. FPG-506330, 2005. 
[22] Russell B.P., Liu T.,Fleck N.A., Desphande V.S.: The soft impact of composite sandwich beams with a square honeycomb core, Int. J. Impact Engng, 2012, 48, 65-81.

[23] Xie Z., Vizzini A.J. and Yang M.: On residual compressive strength prediction of composite sandwich panels after low-velocity impact damage, Sandwich Structures 7: Advancing with Sandwich Structures and Materials, Proc. of $7^{\text {th }}$ Int. Conf. on Sandwich Struct., Aalborg University, Aalborg, Denmark, 2005, pp. 363-372.

[24] Rikards R.: Interlaminar fracture behavior of laminated composites, Computers \& Structures, 2000, 76, pp. 11-18.

[25] Wang S.S., Choi I.: The interface crack between dissimilar anisotropic composite materials, ASME Journal of Applied Mechanics, 1983, 50, pp. 169-178.

[26] Zenkert D.: An introduction to sandwich construction, West Midlands, EMAS Publishing, 1997.

[27] Harik I.E. and Guo M.: Finite element analysis of eccentrically stiffened plates in free vibration, Computers \& Structures, 1993, 49, pp. 1007-1015.

\title{
Porównawcze, geometryczne i doświadczalne badania nowej meta-struktury sandwiczowej i jej klasycznego trójwarstwowego odpowiednika
}

\author{
Streszczenie
}

Celem tej pracy jest porównanie pewnych geometrycznych parametrów i ugięć nowej meta-struktury sandwiczowej i jej klasycznego, trójwarstwowego odpowiednika. Obie struktury są skomponowane z tych samych materiałów i mają te same wymiary zewnętrzne oraz masy ale ich warstwy środkowe (rdzenie) są różne. Rdzeń meta-struktury sandwiczowej jest sam nową strukturą przestrzenną, składającą się z trójwarstwowych prętów. Rdzeń klasycznej struktury sandwiczowej jest warstwą continuum. Aby uczynić to porównanie bardziej ogólnym i przekonującym wprowadzono i zastosowano trzy parametry geometryczne: stosunek powierzchni kontaktu, współczynnik międzywarstwowego przylegania i współczynnik wrażliwości udarowej. Ugięcia tych struktur, swobodnie podpartych na krawędziach i obciążonych siłami statycznymi w środku przęsła, zostały zmierzone i są prezentowane w tej pracy. Potencjalne korzyści nowej meta-struktury są krótko naszkicowane. 